\title{
Implications of the activational cleavage of PAR1 by MMP-1 in human breast cancer
}

\author{
Francesca A. Mercuria , Erik W. Thompson ${ }^{a, b}$ \\ ${ }^{a}$ Department of Surgery, University of Melbourne; 'b St. Vincent's Institute, St. Vincent's Hospital, \\ Fitzroy, Vic., Australia.
}

\section{Citation of original article:}

A. Boire, L. Covic, A. Agarwal, S. Jacques, S. Sherifi, A. Kuliopulos. PAR1 is a matrix metalloprotease-1 receptor that promotes invasion and tumorigenesis of breast cancer cells. Cell 2005; 120(3): 303-13.

\begin{abstract}
of the original article
Protease-activated receptors (PARs) are a unique class of G protein-coupled receptors that play critical roles in thrombosis, inflammation, and vascular biology. PAR1 is proposed to be involved in the invasive and metastatic processes of various cancers. However, the protease responsible for activating the proinvasive functions of PAR1 remains to be identified. Here, we show that expression of PAR1 is both required and sufficient to promote growth and invasion of breast carcinoma cells in a xenograft model. Further, we show that the matrix metalloprotease, MMP-1, functions as a protease agonist of PAR1 cleaving the receptor at the proper site to generate PAR1dependent $\mathrm{Ca}^{2+}$ signals and migration. MMP-1 activity is derived from fibroblasts and is absent from the breast cancer cells. These results demonstrate that MMP-1 in the stromal-tumor microenvironment can alter the behavior of cancer cells through PAR1 to promote cell migration and invasion.
\end{abstract}

\section{Review}

Matrix metalloproteinases (MMPs) represent a family of zinc- and calcium-dependent proteolytic enzymes. To date 26 structurally related MMPs have been identified and between them they are responsible for the degradation of extracellular matrix (ECM) proteins such as: collagens, proteoglycans, elastins, but also a growing number of important non-structural proteins such as growth factors, cytokines, chemokines, matricellular proteins and cell surface receptors for each of these (reviewed in refs [1] and [2]). MMPs remain largely

Correspondence to: Erik W. Thompson, Department of Surgery, University of Melbourne, St. Vincent's Hospital, 29 Regent Street, Fitzroy, Vic. 3065, Australia. E-mail: rik@medstv.unimelb.edu.au; Tel: +61 39288 2569; Fax: +61392882605

Received 15/08/05

Accepted 23/08/05

$\mathrm{BCO} / 453 / 2005 / \mathrm{JC}$ responsible for normal tissue remodelling and are also associated with pathological conditions such as inflammation, arthritis, diabetic nephropathy, atherosclerosis, angiogenesis and tumour invasion and metastasis. While the traditional view has been that MMPs play a pivotal role in tumour growth and invasion through structural clearance [3,4], a much broader gamut of activities has emerged with the revelation of their rather specific and potent additional effects in either activating or inactivating a host of important cellular pathways. Numerous in vivo studies provide evidence that enhanced production of MMPs or their inhibitors is associated with a more aggressive growth and poor clinical outcome in breast carcinomas (reviewed in ref. [2]).

The novel study by Boire and colleagues [5], reviewed here, extends the repertoire of non-structural cleavage associated with MMPs to the activation 
of protease-activated receptor 1 (PAR1) by a matrix metalloproteinase, MMP-1. MMP-1 cleavage also allowed PAR1 to retain its $\mathrm{Ca}^{2+}$ influx functionality. To date four different PARs have been identified, PAR1, PAR2, PAR3 and PAR4, and until now their activation by MMPs has not been reported. Soluble proteases can cleave PARs to expose a tethered ligand that binds and activates the cleaved receptor. Previously identified activating proteases include the serine proteases thrombin, plasmin, trypsin, and factor $\mathrm{Xa}$, as well as activated protein C (APC), Granzyme-A and Gingipains-R (reviewed in ref. [6]). The current work is an exciting finding since the authors previously showed that PAR1 expression levels correlated with the degree of invasiveness in both primary breast tissue specimens and established cancer cell lines [7]. Furthermore, high levels of PAR1 messenger RNA (mRNA) were found in infiltrating ductal carcinoma and very low amounts in normal and pre-malignant atypical intraductal hyperplasia [8].

MMP-1, identified here as the activating ligand for PAR1, was also recently launched into the limelight as a potential marker for progression from atypical ductal hyperplasis $(A D H)$, a common benign breast disease, to breast malignancy [9]. Of 540 gene products associated with this progression, MMP-1 showed the highest ( $\sim 35$-fold) increase in $A D H$ associated with cancer over ADH with no evidence of cancer within 5 years of ADH diagnosis. MMP-1 has also received attention through the discovery of promoter polymorphisms which lead to its increased expression [10], although there appears to be differing opinions. There is some correlative evidence in cell lines [11], however this has been buffered by studies showing no evidence of increased allelic frequencies in breast cancers $[12,13]$.

The issue of which cells express MMP-1 in breast lesions remains somewhat controversial. The underlying principle for the current study is that the breast cancer cells require stromal fibroblast-derived MMP-1 to activate PAR1, which in turn promotes cell migration towards the stroma. Boire and colleagues [5] concluded that MMP-1 from the fibroblastic stroma promoted growth and invasion of breast carcinoma cells, as the MDA-MB-231 cells they used clearly lacked MMP-1 expression in vitro. Indeed, our recent studies on host and tumoural contributions to MMPs produced in xenografts, including the MDA-MB-231 cells as well as other better differentiated and patient proximal xenografts, showed very limited expression of tumoural MMPs, and strong expression of stromal (mouse) MMPs. Unfortunately MMP-1 was not tested, but MMP-2, -9, -11, -13 and MT1-, MT2- and MT3-MMP (MT, membrane type) human mRNA levels were generally low in contrast to strong inductions of the murine counterparts of all except MT2-MMP [14].
We would anticipate that MMP-1 would behave the same way, with predominantly stromal expression, and induction over the resting mammary stroma. Certainly, in studies of clinical material, high levels of MMP-1 expression have been associated with the fibroblastic stromal cells adjacent to the tumour cells [15-18]. However a recent immunohistochemical study by Bachmeier and colleagues [19] demonstrated that the majority of positive labelling for MMP1 (and $-3,-2$ and -9 ) in 12 tumour samples was in the tumour cells, rather than the peri-tumoural stroma cells. They showed a significantly higher proportion of MMP-positive tumour cells at the tumour periphery rather than the more solid tumour centre. Although Poola and colleagues [9] did find immunoreactivity in both the parenchymal and stromal tissue, they detected intensely higher levels in the stromal tissues. Induction of stromal MMP-1 may be regulated by the production of extracellular matrix metalloproteinase inducer (EMMPRIN) by the tumour cells [20]. EMMPRIN not only induces a range of MMPs in stromal cells, but also induces itself [21], and its overexpression in MDA-MB-436 human breast cancer cells makes them highly invasive and metastatic $[22,23]$. Further studies will be required both in model systems and clinical material to address the source of MMP-1, and the possibility of autocrine activation of PAR 1 by MMP-1, although, since MMP-1 is a soluble enzyme, it may be able to activate PAR1 whether produced by the tumour or stroma.

It bears noting that while the MDA-MB-231 cells used in the current study do not produce any MMP-1 (in agreement with our own studies [24]), others have shown by reverse transcription polymerase chain reaction (RT-PCR) $[25,26]$ and by Western blot and casein-zymography [27] that these cells can have high levels of MMP-1. Moreover, Brinkerhoff and coworkers have shown that the MMP-1 produced by their MDA-MB-231 cells is important for their invasive capacity [28]. It would be interesting to use an alternative source of MDA-MB-231 cells that has MMP-1, establish whether PAR1 becomes constitutively activated, and examine how that would affect the siRNA results. It is surprising, in fact, that MDAMB-231 cells do not express MMP-1, because they constitutively express a number of mesenchymal transcription factors such as c-ets- 1 typically found in mesenchymal cells, and typically associated with MMP-1 expression [24,29]. Such indications are supportive of an epithelial-to-mesenchymal transition (EMT) as a mode of progression in all carcinomas, including breast, and MMP expression is closely associated with the EMT [30].

The choice of oestrogen-dependent MCF-7 breast cancer cells for transfection with PAR1 or the non-functional mutant ( $\mathrm{F} 43 \mathrm{~A})$ opens the door to 
speculation about the potential role of the PAR1/MMP-1 axis in progression to hormone independence. The PAR1 transfected MCF-7 cells showed increased migration and invasion through Matrigel, and increased tumour growth was seen in mice injected with the PAR1/N55 clone. Although not specified, one assumes that Matrigel was not used, and in our hands MCF-7 take very poorly in nude mice without Matrigel enhancement [31]. Similarly, it appears that the experiments were performed in intact (i.e. non-ovariectomized) mice without additional oestrogen supplementation, and again, this would be essential for most MCF-7 isolates. Thus, the paper hints at an oestrogen-independent effect of PAR1, and this very exciting suggestion should be followed up with formal studies in ovariectomized mice [32].

The lower frequency of MMP-1 expression in human breast cancer compared to other MMPs [18] is intriguing, and is perhaps consistent with the low expression in cancer-unassociated ADH [9]. Unfortunately, no clinical follow up data were available in the Okada study. It begs the question as to whether MMP-1 is solely responsible for PAR1 activation in vivo. Admittedly, extensive comparative testing with a number of other MMPs by the authors, as well as parallel results with MMP-inhibitors and PAR1 inhibitors, suggest this could be the case, but these were limited by the availability of recombinant MMPs. Certainly, we have also seen considerable inhibition of tumour growth in the MDA-MB-231 mammary fat pad model with Prinomastat/AG 3340 [33]. This agent selectively avoids MMP-1 $(\mathrm{Ki}=8.3 \mathrm{nM})$ compared to MMP-2 and $-9(\mathrm{Ki}=0.05 \mathrm{nM})$, and MT1MMP $(\mathrm{Ki}=0.33 \mathrm{nM})$ [34]. It does, however, show substantial inhibition of MMP-13 $(\mathrm{Ki}=0.03 \mathrm{nM})$ [34], another interstitial collagenase [35]. It will be interesting to determine whether MMP-13 may also have PAR1 activating activity. Although limited information exists on the expression of MMP-13 in clinical breast cancers, it has shown a compelling expression distribution close to disturbances in the basement membrane of ductal carnicoma in situ (DCIS) [36], and we found it strongly induced in the host tissue associated with all breast cancer xenografts we studied [14].

Thus, the work under review builds on a substantial history of MMP-1 in human breast cancer from the perspectives of promoter polymorphism, paracrine induction and production, epithelial-to-mesenchymal transition, and most recently, a predictive role in progression from $\mathrm{ADH}$. As asserted by both the authors and the comments of Pei [37], given the problems encountered with MMP-inhibition clinically $[3,38]$ the potential for targeting a downstream mediator such as PAR1 for blocking the progression and angiogenesis of invasive and metastatic breast cancers is highly attractive. The work under review is an exciting development.

\section{References}

1. Sternlicht MD, Werb Z. How matrix metalloproteinases regulate cell behavior. Annu Rev Cell Dev Biol 2001; 17: 463-516.

2. Egeblad M, Werb Z. New functions for the matrix metalloproteinases in cancer progression. Nat Rev Cancer 2002; 2(3): 161-174.

3. Overall CM, Lopez-Otin C. Strategies for MMP inhibition in cancer: innovations for the post-trial era. Nat Rev Cancer 2002; 2(9): 657-672.

4. Noël A, Gilles C, Bajou K, et al. Emerging roles for proteinases in cancer. Invas Metast 1997; 17: 221-239.

5. Boire A, Covic L, Agarwal A, et al. PAR1 is a matrix metalloprotease-1 receptor that promotes invasion and tumorigenesis of breast cancer cells. Cell 2005; 120: 303-313.

6. Ossovskaya VS, Bunnett NW. Protease-activated receptors: contribution to physiology and disease. Physiol Rev 2004; 84: 579-621.

7. Kamath L, Meydani A, Foss F, Kuliopulos A. Signaling from protease-activated receptor-1 inhibits migration and invasion of breast cancer cells. Cancer Res 2001; 61: 5933-5940.

8. Even-Ram S, Uziely B, Cohen P, et al. Thrombin receptor overexpression in malignant and physiological invasion processes. Nat Med 1998; 4: 909-914.

9. Poola I, DeWitty RL, Marshalleck JJ, et al. Identification of MMP-1 as a putative breast cancer predictive marker by global gene expression analysis. Nat Med 2005; 11: 481-483.

10. Biondi ML, Turri O, Leviti S, et al. MMP1 and MMP3 polymorphisms in promoter regions and cancer. Clin Chem 2000; 46: 2023-2024.

11. Tower GB, Coon $\mathrm{Cl}$, Brinckerhoff CE. The $2 \mathrm{G}$ single nucleotide polymorphism (SNP) in the MMP-1 promoter contributes to high levels of MMP-1 transcription in MCF-7/ADR breast cancer cells. Breast Cancer Res Treat 2003; 82: 75-82.

12. Przybylowska K, Zielinska J, Zadrozny M, Krawczyk T, Kulig A, Wozniak $P$, et al. An association between the matrix metalloproteinase 1 promoter gene polymorphism and lymphnode metastasis in breast cancer. $J$ Exp Clin Cancer Res 2004; 23: 121-125.

13. Ghilardi G, Biondi ML, Caputo $M$, et al. A single nucleotide polymorphism in the matrix metalloproteinase-3 promoter enhances breast cancer susceptibility. Clin Cancer Res 2002; 8: 3820-3823.

14. Lafleur MA, Drew AF, de Sousa EL, et al. Upregulation of matrix metalloproteinases (MMPs) in breast cancer xenografts: a major induction of stromal MMP-13. Int $J$ Cancer 2005; 114: 544-554.

15. Brummer O, Athar S, Riethdorf L, et al. Matrix-metalloproteinases 1, 2, and 3 and their tissue inhibitors 1 and 2 in benign and malignant breast lesions: an in situ hybridization study. Virchows Arch 1999; 435: 566-573.

16. Basset P, Okada A, Chenard MP, et al. Matrix metalloproteinases as stromal effectors of human carcinoma progression: therapeutic implications. Matrix Biol 1997; 15: 535-541. 
17. Heppner KJ, Matrisian LM, Jensen RA, Rodgers WH. Expression of most matrix metalloproteinase family members in breast cancer represents a tumor-induced host response. Am J Pathol 1996; 149: 273-282.

18. Okada A, Bellocq JP, Rouyer N, et al. Membrane-type matrix metalloproteinase (MT-MMP) gene is expressed in stromal cells of human colon, breast, and head and neck carcinomas. Proc Natl Acad Sci USA 1995; 92: 2730-2734.

19. Bachmeier BE, Rohrbach H, De Waal J, et al. Enhanced expression and activation of major matrix metalloproteinases in distinct topographic areas of invasive breast carcinomas. Int J Oncol 2005; 26: 1203-1207.

20. Sun J, Hemler ME. Regulation of MMP-1 and MMP-2 production through CD147/extracellular matrix metalloproteinase inducer interactions. Cancer Res 2001; 61: 2276-2281.

21. Tang Y, Kesavan P, Nakada MT, Yan L. Tumor-stroma interaction: positive feedback regulation of extracellular matrix metalloproteinase inducer (EMMPRIN) expression and matrix metalloproteinase-dependent generation of soluble EMMPRIN. Mol Cancer Res 2004; 2: 73-80.

22. Zucker S, Hymowitz M, Rollo EE, et al. Tumorigenic potential of extracellular matrix metalloproteinase inducer. Am J Pathol 2001; 158: 1921-1928.

23. Toole BP. Emmprin (CD147), a cell surface regulator of matrix metalloproteinase production and function. Curr Top Dev Biol 2003; 54: 371-389.

24. Gilles C, Polette M, Birembaut P, Brunner N, Thompson EW. Expression of c-ets-1 mRNA is associated with an invasive, EMT-derived phenotype in breast carcinoma cell lines. Clin Exp Metast 1997; 15: 519-526.

25. Balduyck M, Zerimech F, Gouyer V, Lemaire R, Hemon B, Grard G, et al. Specific expression of matrix metalloproteinases 1, 3, 9 and 13 associated with invasiveness of breast cancer cells in vitro. Clin Exp Metast 2000; 18: 171-178.

26. Kousidou OC, Roussidis AE, Theocharis AD, Karamanos NK. Expression of MMPs and TIMPs genes in human breast cancer epithelial cells depends on cell culture conditions and is associated with their invasive potential. Anticancer Res 2004; 24: 4025-4030.

27. Bachmeier BE, Nerlich AG, Lichtinghagen R, Sommerhoff CP. Matrix metalloproteinases (MMPs) in breast cancer cell lines of different tumorigenicity. Anticancer Res 2001; 21: 3821-3828.
28. Benbow U, Schoenermark MP, Orndorff KA, et al. Human breast cancer cells activate procollagenase-1 and invade type I collagen: invasion is inhibited by all-trans retinoic acid. Clin Exp Metast 1999; 17: 231-238.

29. Behrens P, Rothe M, Wellmann A, et al. The Ets-1 transcription factor is up-regulated together with MMP 1 and MMP 9 in the stroma of pre-invasive breast cancer. J Pathol 2001; 194: 43-50.

30. Gilles C, Newgreen D, Sato H, Thompson EW. Matrix metalloproteases and epithelial-to mesenchymal transition: implications for carcinoma metastasis. In: Savagner $P$ (Ed.). Rise and Fall of Epithelial Phenotype (web version at www.eurekah.com). Georgetown, TX: Landes Bioscience Publishers; 2004: 297-315.

31. Mullen P, Ritchie A, Langdon SP, Miller WR. Effect of matrigel on the tumorigenicity of human breast and ovarian carcinoma cell lines. Int J Cancer 1996; 67: 816-820.

32. Clarke R, Leonessa F, Brunner N, Thompson EW. In vitro models of human breast cancer. In: Harris JR, Lippman ME, Morrow M, Hellman S (Eds). Diseases of the Breast. Philadelphia: J.B. Lippincott Co.; 2000: 335-354.

33. Waltham M, Tester A, Ruangpanit N, et al. Prinomastat inhibits primary tumor growth and retards osteolytic disease in xenograft models of breast cancer metastasis. 23rd Annual San Antonio Breast Cancer Symposium. San Antonio, TX, 6-9 December, 2000.

34. Shalinsky DR, Brekken J, Zou H, et al. Broad antitumor and antiangiogenic activities of AG3340, a potent and selective MMP inhibitor undergoing advanced oncology clinical trials. Inhibition of Matrix Metalloproteinases. Ann NY Acad Sci 1999; 68: 236-270.

35. Uria JA, Stahle-Backdahl M, Seiki M, et al. Regulation of collagenase-3 expression in human breast carcinomas is mediated by stromal-epithelial cell interactions. Cancer Res 1997; 57: 4882-4888.

36. Nielsen BS, Rank F, Lopez JM, et al. Collagenase-3 expression in breast myofibroblasts as a molecular marker of transition of ductal carcinoma in situ lesions to invasive ductal carcinomas. Cancer Res 2001; 61: 7091-7100.

37. Pei D. Matrix metalloproteinases target proteaseactivated receptors on the tumor cell surface. Cancer Cell 2005; 7: 207-208.

38. Coussens LM, Fingleton B, Matrisian LM. Matrix metalloproteinase inhibitors and cancer: trials and tribulations. Science 2002; 295: 2387-2392. 